\title{
DESPENALIZACIÓN DE LAS RELACIONES SEXUALES EN MENORES DE EDAD
}

\author{
TAFUR GUPIOC, Esperanza ${ }^{249}$
}

SUMARIO: 1. Problemática judicial. - 2. La despenalización de las relaciones sexuales. -3 . Recomendaciones y conclusiones.

\section{RESUMEN}

Los delitos contra la libertad sexual e indemnidad sexuales son los que han sufrido el mayor número de modificaciones en el ordenamiento penal, especialmente con las leyes 28251 que varió por completo el concepto de violación sexual y 28704 que cambio diversos artículos del código penal, incrementándose la carcelería de las personas entre los 14 a 18 años sin importar que la relación sexual sea consentida o con plena capacidad; es decir desconociendo el proceso de maduración sexual y psicológica que se produce en esta etapa del desarrollo biológico de las personas. La despenalización de las relaciones sexuales consensuadas en menores de edad, si bien es cierto sería necesaria, resulta prematuro por cuanto el Estado previamente debe desarrollar una adecuada política dirigida a la prevención que incida en las áreas social, económica, educacional y de capacitación familiar urbana y recreacional principalmente. Se requiere de una reforma integral que comprenda esos aspectos atendiendo no solamente la normativa civil, penal, constitucional de los niños y adolescentes, sino también los aspectos sociológicos y psicológicos.

Palabras clave: Relaciones sexuales en menores de edad, despenalización, formación integral, educación responsable, capacitación en asuntos de familia.

\section{ABSTRACT}

Crimes against sexual freedom and sexual indemnity are those who have suffered the greatest number of changes in the criminal justice system, particularly laws that varied from 28251 whole concept of sexual violation and 28704 to change various articles of the criminal code, increasing the forcible detention of people between 14 to 18 years regardless of sex is consensual or full capacity, i.e. ignoring the sexual maturation and psychological that occurs at this stage of the biological development of people. The decriminalization of consensual sex among minors, although it would be necessary, it is premature because the previously state must develop an appropriate policy aimed at preventing

\footnotetext{
${ }^{249}$ Presidenta de la Sala Mixta de Chachapoyas.
} 


\section{Key words:}

\section{ANTECEDENTE}

Entre los delitos que más modificaciones ha sufrido en nuestro ordenamiento penal, están los delitos contra la libertad sexual e indemnidad sexuales, teniendo mayor resonancia a partir de la Ley $\mathrm{N}^{\mathrm{o}} 28251$ que modificó por completo el concepto de violación sexual que tenía desde el Código Penal de 1924, luego con la dación de la Ley No 28704 publicada el 05 de abril del año 2006, se modificaron diversos artículos del Código Penal, incrementándose las penas privativas de la libertad de las personas entre los 14 a los 18 años de edad, sin importar que sea consentida o con plena capacidad.

Antes de esta última reforma, el libre ejercicio de la sexualidad se daba a partir de los catorce años en que la persona podía ejercer tal disposición, sin más limitaciones que sus propias decisiones, el respeto a la a la libertad ajena y las prohibiciones morales y otras derivadas de las normas jurídicas; sólo eran castigados el acto sexual o análogo que se practicaba utilizando la violencia o grave amenaza, colocando a la víctima en estado de inconsciencia o en imposibilidad de resistir o mediante el engaño; es decir, el Estado protegía la indemnidad sexual de los menores hasta los catorce años de edad, mientras que con la Ley $\mathrm{N}^{\circ} 28704$ dicho bien jurídico se extiende de catorce a dieciocho años, desconociendo el proceso de maduración sexual y psicológica que se da en esta etapa.

Con esta ley toda relación sexual que tenga uno de los intervinientes (varón o mujer) menor de dieciocho años y mayor de catorce años, es considerado como delito, sin importar se haya producido en una relación consentida o afectiva o mediando la violencia o amenaza, estableciéndose el quantum de la pena no menor de veinticinco ni mayor de treinta años, que debía purgarse en su integridad, pues la referida ley proscribía el acogimiento de algún beneficio penitenciario, como semilibertad, liberación condicional, indulto, redención o conmutación de pena.

La dación de la ley nos trajo la polémica de sancionar penalmente a una pareja que tenía una relación sexual consentida con un adolescente mayor de catorce años, porque se sostenía que se trataba de una norma irrazonable dado a que nuestra realidad nos indicaba que los adolescentes se inician, aún muy jóvenes sexualmente y no necesariamente mediante violencia sexual, sino más bien otorgando su consentimiento, es por ello que analizada dicha norma en todo su contexto podía originar que la mitad de los jóvenes podrían ser condenados autores de la comisión del Delito contra la Libertad Sexual - Violación sexual de menor de edad.

Asimismo en su oportunidad originó que en la Maternidad de Lima así como en otros centros hospitalarios, las madres adolescentes sean retenidas, entrevistadas y sus parejas denunciadas o investigadas por violación sexual de menor de edad, a pesar de que según el Código Civil, los menores entre dieciséis y dieciocho años de edad podían contraer matrimonio mediante autorización judicial y permiso de los padres.

La doctrina nacional criticó severamente esta modificación, muchos la consideraron inconstitucional y violadora de principios de Derecho Penal. En la judicatura nacional también se cuestionó la vigencia de esta regulación, y algunos órganos jurisdiccionales, al considerarla atentatoria de dispositivos constitucionales, no la aplicaron en casos concretos 
que iban conociendo, en mérito al control difuso de la constitucionalidad de las leyes (artículo 138, segundo párrafo, de la Constitución Política de 1993).

\section{Problemática Judicial}

Siendo el Juez quien aplica la ley, al estar considerado como delito y con penas sumamente elevadas como la estatuida en el inciso 3 del Artículo $173^{\circ}$ del Código Penal (no menor de veinticinco ni mayor de treinta años de pena privativa de libertad), aunque conscientes de la desproporción de la pena, un acto que se considera impune en ciertas circunstancias tiene que aplicarse con obligación; para lo cual no tiene lugar el considerar la idiosincrasia, costumbres o que sea el Perú un país pluricultural, o que en las zonas alto andinas y de comunidades nativas, el inicio de las relaciones sexuales y convivenciales son tempranas y cuentan con la aceptación y apoyo de los padres y familiares que tienen que soportar el quedarse sin el padre adolescente o mayor de edad que tiene que purgar carcelería por violación sexual de menor.

En cuanto a las relaciones sexuales entre menores de dieciocho años de edad, los casos vistos por los Juzgados de Familia o Mixtos son aquellos en los que se ha conocido a través de los jóvenes adolescentes que fueron reportados como parturientas, con síntomas o amenaza de aborto por los centros de salud que en la mayoría de los casos, mantuvieron relaciones sexuales con otros adolescentes a través de relaciones de enamorados pero que no planificaron un embarazo y que hay renuencia en afrontar responsabilidades paternas $o$ convivenciales y son denunciados ante las Fiscalías de Familia para instaurar la apertura del proceso (Artículo $204^{\circ}$ del Código de los Niños y Adolescentes) y luego dar lugar a tener por promovida la acción (Artículo $208^{\circ}$ del Código de los Niños y Adolescentes) por el Juez, cuando ambos son objeto de protección de su indemnidad sexual consagrada en la Convención sobre los Derechos del Niño.

La praxis judicial ha tenido que implementar mecanismos para limitar el ius puniendi del Estado, frente a una actitud cada vez más de precocidad sexual en los adolescentes, a través de sentencias judiciales y plenos jurisdiccionales que sirven de guía para no lesionar los intereses de los propios adolescentes, a la familia, su dignidad y desarrollo de personalidad, dejando la sanción de las conductas típicas, antijurídicas y culpables para quienes lo merecen.

Otras de las dificultades generadas con la vigencia de la penalización de las relaciones sexuales entre menores se ha extendido a otros delitos derogados tácitamente, por tener menos penalidad, como son los casos de seducción (artículo $175^{\circ}$ del Código Penal), los de favorecimiento a la prostitución (artículo $179^{\circ}$ inciso 1 del Código Penal), la colisión con el Artículo $179^{\circ}$-A sobre acceso carnal o acto análogo con adolescentes a cambio de dinero, el delito de Rufianismo (artículo $180^{\circ}$ del Código Penal) y el delito de Proxenetismo (artículo $181^{\circ}$ inciso 1 del Código Penal). De igual modo, con el Artículo $241^{\circ}$ inciso 1 del Código Civil que faculta al Juez civil dispensar del impedimento por adolescencia, para permitir el matrimonio de menores con dieciséis años cumplidos y tengan voluntad de casarse, y del artículo $244^{\circ}$ del mismo Código, referido al matrimonio de menores con asentimiento expreso de sus padres. 
En este acto considero oportuno relievar el tratamiento judicial que se ha dado para uniformizar criterios jurisprudenciales a nivel nacional sobre este tema:

1. Acuerdo Plenario $\mathbf{N}^{\mathbf{3}} \mathbf{7 - 2 0 0 7 / C J - 1 1 6}$ de fecha 16 de noviembre de dos mil siete donde se estableció con carácter de doctrina legal que deben desarrollarse propuestas jurisprudenciales que permitan alcanzar desde la determinación judicial de la pena una proporcionalidad concreta, adecuada y equitativa en base a las circunstancias particulares del caso y a las condiciones especiales de los sujetos del delito. Siendo primordial para la determinación del quantum de la pena la concurrencia de factores complementarios de atenuación para cada caso concreto los siguientes requisitos:

a. Que la diferencia etarea entre los sujetos activo y pasivo no sea excesiva.

b. Que exista entre los sujetos activo y pasivo un vínculo sentimental carente de impedimentos o tolerado socialmente.

c. Que las costumbres y percepción cultural de los sujetos postule la realización de prácticas sexuales o de convivencia o temprana edad.

d. La admisión o aceptación voluntaria en la causa por el sujeto activo de las prácticas sexuales realizadas.

Consecuentemente, desde esta perspectiva deberá atenuarse la pena, en los casos del Artículo $173^{\circ}$, inciso 3) del Código Penal hasta los límites considerados para los delitos tipificados en los artículos $175^{\circ}$ y $179^{\circ}$-A del Código acotado que tratan de conductas semejantes, en las que incluso median el engaño y la prestación económica como determinantes de la práctica sexual antijurídica.

Asimismo se dejó establecido que cuando la relación sexual sea voluntaria y el sujeto pasivo tiene entre dieciséis y dieciocho año de edad, es aplicable el artículo $20^{\circ}$, inciso 10 del Código Penal que regula la institución del consentimiento, en tanto se den los presupuestos legales penales y civiles correspondientes de acuerdo a la aplicación de las normas del Código Civil (Artículos $44^{\circ}, 46^{\circ}$ y $241^{\circ}$ ).

2. Acuerdo Plenario $\mathbf{N}^{\mathbf{0}}$ 4-2008/CJ-116, del 18 de julio de dos mil ocho, las Salas Penales Permanentes, Transitorias y Especial de la Corte Suprema de Justicia de la República, por unanimidad acordaron establecer como doctrina legal la exención de responsabilidad penal por consentimiento del titular del bien jurídico afectado, aplicable al delito de violación sexual a que se refiere el artículo $173^{\circ}$ inciso 3) del Código Penal, debiendo ampliarse el duodécimo fundamento jurídico del Acuerdo Plenario N ${ }^{\mathrm{a}}$ 7-2007/CJ a toda relación sexual voluntaria mantenido con adolescentes de catorce a dieciocho años de edad; por lo tanto, es necesario hacer hincapié que carece de trascendencia la diferencia de edades que exista entre el sujeto activo y pasivo o el vínculo sentimental entre ellos, en cuanto no medie violencia, grave amenaza o engaño este último sólo relevante para el delito de seducción.

3. Acuerdo Plenario $\mathbf{N}^{\mathbf{a}} \mathbf{1 - 2 0 1 1 / C J - 1 1 6}$, del seis de diciembre de dos mil once sobre la apreciación de la prueba a efectos de evitar la victimización secundaria, en especial de los menores de edad, mermando las aflicciones de quien es pasible de abuso sexual, estableciendo que se debe tener en cuenta las siguientes reglas:

a. Reserva de las actuaciones judiciales;

b. Preservación de la identidad de la víctima; 
c. Promover y fomentar la actuación de única declaración de la víctima. Esta regla es obligatoria en el caso de menores de edad, valiéndose para ello de las directivas establecidas por el Ministerio Público en la utilización de la Cámara Gesell, especialmente respecto a la completitud, exhaustividad y contradicción de la declaración.

De esta manera la máxima instancia judicial del país ha buscado solucionar los problemas que trajo consigo la Ley $\mathrm{N}^{\mathrm{o}} 28704$, cuya vigencia motivó que nos interroguemos: ¿Acaso, no estaba induciendo a los adolescentes a abortar, atar o abandonar a sus hijos recién nacidos en las vías públicas, para que no se conozca su identidad, y evitar que el padre de la criatura sea denunciado, procesado y eventualmente sancionado con penas que oscilan entre los veinticinco y treinta años de privación de la libertad?

Sin duda, la intención del legislador al promulgar la Ley No 28704 para endurecer las penas para los delitos contra la libertad sexual en menor de edad, las sobre criminaliza con el incremento exagerado de las penas, solo de modo ficticio aparecen como una mayor protección a la víctima, pero en la práctica, no parece haber contribuido a una mayor eficacia preventivo general o a la mayor tutela de los bienes jurídicos del Derecho Penal sexual, sino por el contrario, esta regulación simbólica sirvió como una simple salida facilista del Estado frente a la demanda social.

\section{La despenalización de las relaciones sexuales}

La Comisión de la Mujer y Familia del Congreso de la República ha admitido, la propuesta de despenalizar las relaciones sexuales consensuadas de los menores entre catorce y menos de dieciocho de edad, lo cual nuevamente ha reabierto el debate conflictivo en los diversos sectores de la población del que no puede ser ajeno el Poder Judicial; siendo muchas voces que se están dando a favor y en contra; sobre todo a partir de los proyectos Ley $\mathrm{N}^{\circ} 476$ /2011-CR a iniciativa de la congresista Rosa Mavila León que propone modificar el artículo $173^{\circ}$ del Código Penal y el N`651/2011-CR a iniciativa de la congresista Karla Schaefer Cuculiza, los mismos que tienen por objeto despenalizar las relaciones sexuales de los y las adolescentes siempre que tales relaciones sean consentidas, suprimiendo el inciso 3 del artículo $173^{\circ}$, artículo $170^{\circ}, 173^{\circ}$-A y $175^{\circ}$ del Código Penal el cual sanciona como delito de violación sexual entre catorce y menos de dieciocho de edad.

Cuando se promulgó la Ley $\mathrm{N}^{\circ} 28704$ el 05 de abril de 2006, muchos abogados y juristas criticaron duramente la posición adoptada por el Legislador, atribuyéndole que con dicha regularización se declaraba la muerte de la sexualidad de los adolescentes, por atentar contra el libre desarrollo de la personalidad y la dignidad humana, además de retrógrada y autoritaria, ya que los adolescentes también tienen derecho al ejercicio de la libertad sexual y a manifestar sus sentimientos, más aún si forman parte de la realización de su proyecto personal y de su modo de vida; el derecho penal no podía sustituir la adecuada educación sexual o la moral familiar menos de ser la primera ratio en la protección de los bienes jurídicos, se debe proteger la indemnidad sexual o preservar el desarrollo sexual en la medida que el portador o titular del bien no se encuentre en capacidad cognitiva y valorativa de protegerlos; pero si goza de auto determinación o una mínima capacidad de disposición, el Derecho Penal no debe criminalizar dicha manifestación espontánea de libertad, con una pena tan severa. 
En este sentido, la presente ponencia busca realizar un análisis socio jurídico, que permita contextualizar la referida propuesta y analizar los costes sociales que implicaría su puesta en práctica, sobre todo en una sociedad donde la juventud no está debidamente preparada para ejercer su libertad de autonomía sexual.

No es un secreto que los jóvenes peruanos (y los adultos en muchos casos) no tienen idea de esos riesgos. Según el INEI, el 13.5\% de nuestras adolescentes entre 14 y 19 años ya son madres o están embarazadas, y en algunas zonas de la Selva el promedio alcanza el 25\%. Esto se complementa con los miles de abortos clandestinos a los que, arriesgadamente, se someten esas mujeres.

El aspecto sociológico jurídico es que sobre la base de los estudios sociales lo jurídico debe prevenir el incremento de las conductas sociales que ponen en peligro la armonía social y por lo tanto debemos dar las condiciones legales para que siga siendo así y no se constituya en delito, lo que debemos Preguntarnos ¿Qué está sucediendo en nuestra sociedad peruana para que los menores inicien su vida sexual de manera temprana, que los motiva? ¿Se conoce el perfil de los y las adolescentes que inician su vida sexual temprana? ¿Se ha determinado el impacto social o coste para las familias, el Estado y la sociedad dar tal o cuáles iniciativas legales? ¿Cuál es la respuesta del sector educativo, existe una propuesta de educación sexual integral que se coordinada de manera interinstitucional? ¿Se está tomando en cuenta la realidad cultural, las diferencias en las maneras de pensar y actuar del adolescente de la ciudad y del campo, aun más del adolescente de clase alta con los de condiciones de pobreza?

No se trata de un prejuicio o de querer restringir las libertades de los adolescentes para iniciar su vida sexual con quien les parezca o cuando, pero si bajo, qué condiciones que implique que están preparados para ello y tengan las condiciones para afrontar los efectos de sus decisiones, sobre todo en dentro del grupo etario de 14 a menores de 18 años en muchos casos se encuentran en dependencia económica, es decir están siendo mantenidos por sus padres o familiares, además se encuentran en pleno proceso de formación educativa, aun más su proyecto de vida aún no está claro; con todo ello no se está analizando lo que a futuro representaría mayores embarazos de adolescentes, mayor deserción escolar, estudios sin conclusión sobre todo de las menores mujeres que frustrarían su proyecto de vida, es ¿acaso que esta ley busca perpetuar las relaciones de género del patriarcado, buscando justificar a al varón en su aprovechamiento sexual sobre la mujer?

En síntesis atendiendo a los casos que se conocen en los diversos Juzgados de Familia o Mixtos y los que se conocen como problemática en el ámbito de la sexualidad por la juventud de las diversas regiones del país, me permito adoptar una posición negativa frente a la despenalización de las relaciones sexuales entre menores, porque se podría advertir como reitero precocidad sexual de los adolescentes, el incremento cada vez más de embarazos no deseados ni planificados, que truncan la vida de los adolescentes y merecen mayor y mejor protección legal con inclusión en ámbitos laborales.

Así como por la verificación de pérdida de valores en la sociedad (falta de respeto entre padres e hijos, abuso sexual y maltrato infantil, desintegración de hogares), falta de acercamiento entre padres e hijos para tratar temas de sexualidad que conlleva a la desinformación en el hogar y distorsión de información en otros ámbitos (la calle y la escuela). 
La violencia familiar y sexual a menores generados por familiares del entorno de la víctima adolescente.

El uso y abuso temprano del alcohol y las drogas por parte de niños y adolescentes, que desencadenan en relaciones sexuales, sin protección, con el consiguiente contagio de enfermedades de transmisión sexual.

Por factores culturales y de idiosincrasia en un país pluricultural como el Perú, que desconoce la vigilancia y la participación ciudadana para garantizar los derechos de los niños y adolescentes.

La falta de control en el uso de los adelantos tecnológicos como el internet, telefonía celular, la televisión, que contribuyen a la deficiente información sexual y servicios que lo sitúan en mayor riesgo y vulnerabilidad.

Ahora bien, debo de indicar que mi posición no colisiona con las pautas culturales, las costumbres o la cultura en la que la persona ha formado su personalidad, ya que dichas características merecen el debido respeto de acuerdo a la idiosincrasia del pueblo, tal es así por ejemplo yo soy magistrada de la Corte Superior de Justicia de Amazonas, donde existe diversidad de culturas; es decir es una región pluricultural en la que contamos con un conglomerado de etnias nativas (awahun, huambisas, etc.), así como campesinas que radican en la zonas altas las mismas que por su lejanía recurren a las rondas campesinas; dichas zonas por la interculturalidad existente tienen particularidades entre otros respecto al inicio de la vida sexual de los menores, que son a temprana edad. Es más en la mayoría de las veces la pareja convive y tiene el consentimiento de los padres, motivo por el cual con la aplicación del Acuerdo Plenario No 4-2008/CJ., los casos judicializados han sido resueltos respetando el estrato social y el medio donde se desarrollan.

\section{Recomendaciones}

Considero que la despenalización de las relaciones sexuales en menores de edad, si bien sería necesario, es prematuro, por cuanto previamente el Estado debe desarrollar una política eficaz dirigida a la prevención (relacionada con las variadas áreas del quehacer social-económica, educacional y de capacitación familiar, urbana, de recreación, entre otros.

Implementación de programas que involucren a la familia y la sociedad en su conjunto que tienda a reducir las desigualdades en todos sus ámbitos; vale decir, los niños y adolescentes varones y mujeres tienen derecho a una formación integral y a una educación responsable que les ayude a desarrollar su capacidad de dominar sus impulsos para lograr una personalidad adulta madura y equilibrada.

Desde la perspectiva del Poder Judicial, debe procurarse la especialización y la capacitación permanente en asuntos de familia, con Jueces y personal jurisdiccional comprometido con el quehacer de la juventud y la niñez, capaces de atender los casos sometidos a su jurisdicción, como verdaderos problemas humanos.

Mayor presencia del Poder Judicial en las acciones que desarrolla el Estado y Organismos Multidisciplinarios, en beneficio de la niñez y adolescencia, a fin de que no estén al margen de las discusiones jurídicas o debates legislativos y evitar que se convierta en un simple aplicados de las leyes. 
Debe actualizarse el Código de los Niños y Adolescentes, que debe estar acorde con la normatividad de los convenios internacionales suscritos y ratificados por el Perú, según los requerimientos de desarrollo de éste sector social; especialmente en las medidas que garanticen los derechos de los niños y adolescentes en situación de vulnerabilidad, como los afectados por infecciones de Transmisión Sexual o cáncer; en programas específicos dirigidos a los niños ya adolescentes víctimas de explotación sexual y en la implementación de la justicia alternativa o extrajudicial como las Defensorías de los Niños y Adolescentes que defiendan sus derechos a través de conciliaciones y acuerdos razonados.

Asimismo constituye un imperativo el fortalecimiento del rol de la Policía Nacional (preventivo), rol Fiscal en la gestión de Despachos Fiscales, (víctimas y testigos), (prevención del delito), en la prueba indiciaria; a la postre de plenarios jurisdiccionales no solo el (7-2007/CJ-116;(4-2008/CJ-116) que ha establecido que cuando la víctima sea mayor de catorce años y menor de dieciocho y exista consentimiento de su parte el agente quedara exento de responsabilidad penal, sino también del (1-2011/CJ-116 sobre apreciación de la prueba en delitos contra la libertad sexual); a su vez el compromiso de todas las autoridades a ayudar a los padres de familia y a todo "sujeto de derecho" hacer efectivo el ejercicio pleno de sus derechos al amparo de las normas nacionales e internacionales que el Perú ha suscrito.

\section{Conclusión}

Concluyo refiriendo que necesitamos de una reforma integral que comprenda los aspectos señalados en la presente ponencia, atendiendo no solo a la normativa del derecho penal, derecho civil, derecho de los niños y adolescentes acorde a la carta magna y derecho supranacional. Así como también atender los aspectos sociológicos y psicológicos que permitan una visión sistémica de la problemática.

\section{BIBLIOGRAFIA}

- Código de los niños y adolescentes

_ Código penal

_ Leyes 28251 y 28704

_Acuerdo plenario $\mathrm{N}^{\circ} 4-2008 / \mathrm{CJ}-116$ 18.07.2008. Corte Suprema de Justicia

_Acuerdo plenario N¹-2011/CJ-116 06.12.2011. Corte Suprema de Justicia 